\title{
Life according to television. Implications of genre-specific cultivation effects: The Gratification/Cultivation model
}

\author{
HELENA BILANDZIC and PATRICK RÖSSLER
}

Abstract

The basic assumption of cultivation - more exposure to television leads to more cultivation effects - is examined by reviewing research on genrespecific cultivation. Studies on three genres are included in the review: Crime, soap opera and talk shows. The review indicates differential cultivation effects of the different genres; not all of them are consistent with the basic cultivation hypothesis. Building on these results, a theoretical framework is set up that accounts for possible explanations. The framework starts from the notion of a multi-step cultivation process inherent in current theorizing, ranging from (1) encoding and storage of television information, (2) inferences about the real world, and (3) retrieval and construction of cultivation judgments. This notion is extended by reconceptualizing the 'cultivating' message, integrating uses and gratifications of television viewing and emphasizing the role of personal knowledge and attitudes.

Keywords: cultivation, genre, sociological approaches, psychological approaches, Uses and Gratifications

\section{Introduction}

Cultivation research has considerably changed over the past 30 years. At first sight, one of the major changes appears to be a predominantly methodological improvement: Recent research tends to investigate the impact of genre-specific television use (rather than the impact of overall television use) on the viewers' world views, representing a more specific measure of the amount and the nature of cultural indicators people actually encounter when watching television. However, this development is 
at the surface merely a methodological change. This article will review empirical findings of genre-specific cultivation, analyze its theoretical implications, and finally develop a model that considers present research and extends theoretical assumptions in this field by integrating the Usesand-Gratifications approach.

\section{Changing perspectives: Individual or social, or both?}

Another turn is closely related to research on genre-specific cultivation: Scholars have increasingly focused on the question why cultivation effects occur rather than just asking if and to what extent they occur. This has led to a thorough investigation of the psychological processes forming and modifying cultivation effects (e. g., Hawkins and Pingree, 1990; Potter, 1993; Shrum, 2001). In the work of the cultivation pioneers, George Gerbner and his colleagues (e.g., 1994), this matter was not raised as a necessary condition to understanding television effects. It was argued that cultivation is a social rather than an individual process, and that investigating processes would divert from identifying effects on the societal level (Shanahan and Morgan, 1999: $172 \mathrm{ff}$.). This line of argument creates a dichotomy between analyzing television's influence from a psychological perspective (when investigating psychological processes) or a sociological perspective (when disregarding them). As this seems to be a fundamental question of how cultivation research is conducted, it deserves closer examination.

The goal of cultivation research (and of sociology and social psychology, for that matter) is to find out how people construct social reality. Yet there are diverging positions in the social sciences about how to achieve this goal. Collectivist positions (Durkheim, Parsons) claim that social processes and systems have their own specific laws that function independently of individual actions and motives, and that the individual does not need to be considered when explaining society (Esser, 1999). The position of 'methodological individualism' (Popper, 1999), in contrast, maintains that the explanation of social systems and processes must start by investigating actions and interpretations of individuals. Inferences on society can be drawn by using a predefined rule of aggregation. This differs substantially from a mere psychologism that only considers private motives and individual knowledge; methodological individualism instead emphasizes the social character of such motives and knowledge (Esser, 1999: 29). Studying individual processes does not necessarily mean to ignore society, but rather to pursue a different, widely accepted way of investigating social reality. It represents the first step 
toward explaining television's influence in society without risking artifactual correlations due to ecological fallacy.

Hence, without abandoning the goal of cultivation research, two basic processes have been identified accounting for the television impact on reality construction (Hawkins and Pingree, 1982; Tapper, 1995). The first is a process of encoding and storing television information and the second a process of retrieving information and constructing a judgment from the remembered bits of information (see Figure 1).

\section{Encoding and storing}

Viewers also acquire information incidentally, rather than intentionally, while viewing television. The information from television can be stored semantically (as abstract, schematic knowledge) or episodically (as single events idiosyncratic to the individual).

Whether information will be stored in long-term memory or not depends on a variety of processes, for example selection (people must attend to an information and choose it for processing), rehearsal (the information is kept in working memory for some time and thus accesses longterm memory) or elaboration (adding one's own interpretations and inferences to the actual information; see Ormrod, 1999: $210 \mathrm{ff}$.). Rehearsal is particularly interesting for cultivation, because the repetition of cultural indicators is generally conceived as influential. But the mere repetition of facts is not sufficient; rather, rehearsal is only effective when people relate their existing knowledge to new information. Building on social learning theories (Bandura, 1977), additional influences on encoding and storage can be identified, for example, characteristics of observed people (models) or reinforcement or punishment of an observed behavior.

\section{Retrieval and construction}

When in need of a judgment, people integrate different pieces of information they find appropriate for this purpose (Hawkins and Pingree, 1990; Shapiro, 1991). Not all available information is considered, but only a subset that comes to mind easily - decision heuristics are applied in order to simplify and speed up the process of judging (e. g., Busselle, 2001; Shrum, 1995, 2001). Heuristic processing is likely to occur in survey situations, because people are usually not very involved and may wish to terminate the interview as soon as possible (Shrum, 1997). If judgments are constructed and not reproduced from memory, they are susceptible to the symbolic instruction in the cultivation question (e.g., 


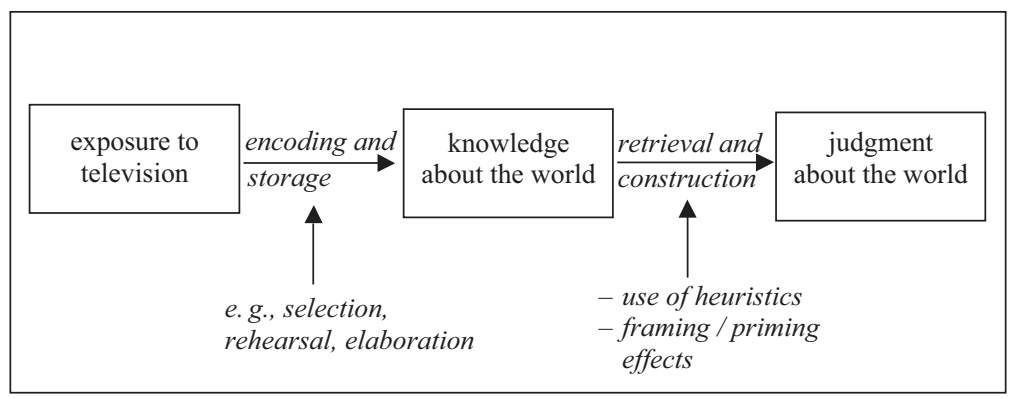

Figure 1. Basic model of the cultivation process

framing effects) and to preceding information in the questionnaire (e.g., priming effects; see Shrum, Wyer, and O'Guinn, 1998).

However plausible this distinction between learning and construction may be, it is still unclear what kind of information viewers actually acquire from television. A television message is very complex and provides information on many different levels. For example, it presents different arguments, facts or actions; it also contains formal features such as cuts, background music or camera movements. Finally, it portrays people with specific characteristics. Moreover, patterns of information vary across different programs. Within the process of encoding and storage, repetition was mentioned as a possible factor among others in retaining information. Yet exposure to the very same depiction on television is obviously a rare event even in a world of frequent reruns. It is important to acknowledge that repetition actually means multiple exposure to similar depictions. But what similarities can be distinguished between two messages? And do the viewers actually recognize them as similar and subsume them under the same category?

One possibility to locate similarities in the world of television is to use the conventional subdivision in genres. Genres are structural entities of television, characterized by similarities in topics, actions and role attributes or stereotypes. One major problem with using genre categories in audience surveys is the worry that "viewers may not define genres in the same way as do researchers" (Morgan and Shanahan, 1997: 6). This, of course, is an objection worth considering. However, viewers normally make use of genre categories in their daily lives to communicate with others about television, and they have no problem recognizing different types of program very quickly and easily (Gehrau, 2001).

If the repetition of certain messages is more probable within the boundaries of a genre, exposure to a genre should be a more appropriate predictor of learning than overall television would. This argument is the 
starting point for a host of studies investigating genre-specific cultivation effects. At the same time, it marks the most pronounced departure from 'traditional' research conducted by Gerbner and his associates who explicitly renounce the use of genre-specific measures and justify their use of overall television exposure with two assumptions (e. g., Gerbner et al., 1994; Gerbner et al., 1979):

1. Television content is homogenous because mass production of programs generates a consistent set of images and messages that conforms to the norms and values of most people to ensure broad acceptance.

2. Television use is unselective and ritualistic: Viewers fit their viewing into their personal time schedule rather than choosing according to content. This is the reason why the most frequent and pertinent patterns of television content cannot be missed by a regular viewer.

Potter (1993) criticizes these assumptions for being unnecessarily axiomatic. Empirical findings have sufficiently proved that both assumptions cannot be maintained (e.g., Hawkins and Pingree, 1981a) - at least, if factual indicators like crime rate or occupational roles are used (which of course differ from genre to genre; e. g., Gerbner and Gross, 1976; Gerbner et al., 1978; Greenberg et al., 1980; Potter et al., 1997), and if non-selectivity is interpreted as a haphazard, random way of viewing (viewers do have specific preferences and compose their individual television fare accordingly; e. g., Heeter, 1988, Youn, 1994). Later on, we will discuss in detail how these assumptions could be modified to save their compelling basic idea.

\section{Rationale of the research review}

If we expect that cultivation starts with some kind of learning process, several assumptions about the relationship between genre exposure and world view can be set up. Basically, the more a viewer watches a genre that contains a particular content feature, the more he or she should retain this particular content feature and be able to reproduce it. In this case, the viewer holds a belief that is semantically related to the portrayal in his or her preferred genre (e.g., crime drama viewing and fear of crime). This leads to the first assumption that guides our research review:

Assumption 1: The relationship between genre viewing and holding semantically related beliefs is positive.

If a belief is not represented in the messages of a genre, then dependent and independent variables are semantically unrelated (e. g., soap opera 
viewing and fear of crime). Again, with learning being the relevant process, beliefs of viewers should correlate less with semantically unrelated genres:

Assumption 2: The relationship between genre viewing and holding semantically unrelated beliefs is weaker than the correlation between genre viewing and holding semantically related beliefs.

The same rationale applies for overall television:

Assumption 3: The correlation between genre viewing and holding semantically related beliefs is stronger than for television viewing in general.

Finally, the activity and involvement should be crucial for potential effects:

Assumption 4: Intensity of learning strengthens the relationship between genre viewing and holding semantically related beliefs.

We will examine these hypotheses based on a review of published empirical research on genre-specific cultivation. The results will provide some evidence on the causality of the relationship between television exposure and social reality beliefs. For instance, if there is a learning effect of television viewing, fear of crime should relate more to crime viewing than to soap opera viewing. If the reverse is true and fear of crime relates more to soap opera viewing, we may start to think about interpreting the process as a coping strategy or an escape behavior of fearful viewers who want to reduce their fear by watching crimeless content.

We will examine these assumptions by reviewing research results on three television genres: (1) Crime drama which is the most prominent genre in cultivation research and which directly relates to traditional cultivation operationalizations like fear of crime or the mean world belief; (2) soap operas that portray problems very differently from crime drama and rather focus on relationships and everyday life; and (3) talk shows that cover a wide range of everyday topics, from normality to deviance. They are supposed to show real people expressing their true opinions, yet there is always some doubt whether the conflicts are spontaneous or staged.

For all three genres, we find sufficient empirical evidence. Certainly there are many more genres that have been investigated under a cultiva- 
tion perspective, but the sheer amount of studies published so far forces us to concentrate on three genres that differ in textual, formal and dramatic attributes.

The studies were first selected from the Communication Abstracts database, searching for the keyword 'cultivation'; only articles on genre-specific cultivation were kept. The references in these articles completed the list. Only studies were included that used (1) a non-experimental design, (2) individual data and (3) indicated effects of overall TV and genrespecific use. This left nine articles for crime genres, five for soap operas and four for talk shows.

Most studies on crime genres (Table 1) report the typical weak relationships between overall television viewing and crime-related beliefs. But seven studies out of nine do not show a positive correlation of crimerelated beliefs with crime viewing. In the studies dealing with soap operas, three out of five do not confirm the first assumption (Table 2), whereas two talk show studies (Table 3) are supportive and one is not. As for the second assumption, in most cases watching other genres leads to more cultivated beliefs than watching the related genre (in six studies out of nine on crime, and two out of four studies on talk shows). Only in one study about soap operas the results comply with cultivation. In regard to crime genres, the third assumption could only be confirmed in two studies; six are not supportive. But the two other genres are partly congruent with the hypothesized notion (soap operas: two studies confirm the assumption, one disconfirms; talk shows: two studies confirm).

The results so far suggest that viewers are differently cultivated according to genre. Results on activity (assumption four) corroborate this: Activity weakens the relationship between viewing and beliefs in two studies on soap operas and one on crime. Only one study on soap operas confirms assumption four.

Our research review raises several interesting questions. First, we may question ourselves whether we ask the right questions in our field work. As Zillmann (1980) states, crime drama does not only consist of violence and aggressive behavior, but stereotypically portrays the victory of the legal system over criminals. Thus it may even distort world views toward safety rather than toward danger. We may be attributing the cultivation potential to the wrong messages: (1) What part of the television message does actually influence the viewer?

Furthermore, we have to reconsider the first step in the basic cultivation model and ask what is actually encoded and stored. What viewers acquire from television is knowledge about the television world, and not about the real world - people usually are able to discern between the two worlds (Shapiro and Lang, 1991). Beliefs seem to depend on how much and which type of information gets transferred from television knowledge to real-world-knowledge - this may differ from genre to 


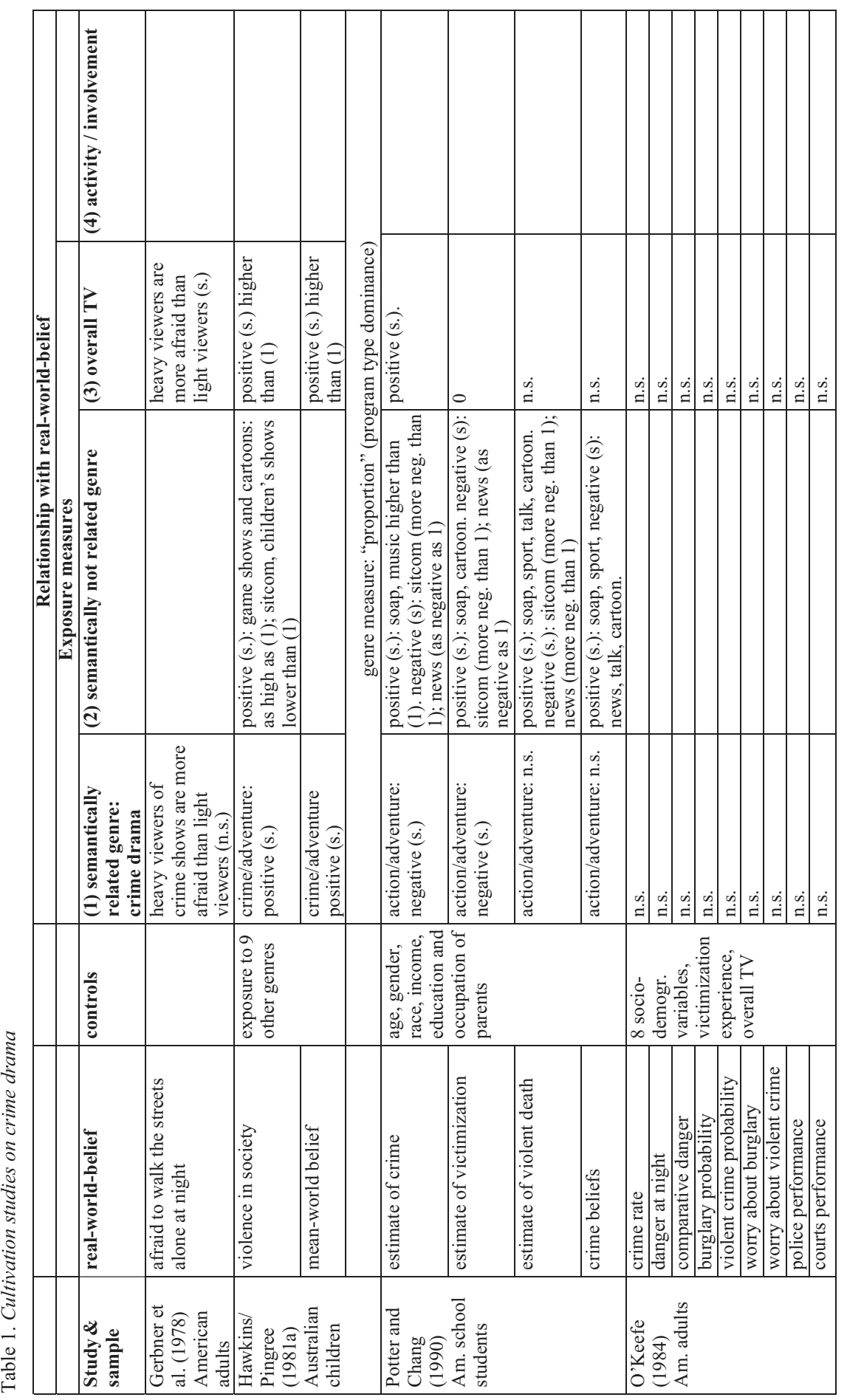

Bereitgestellt von | Universitaetsbibliothek Augsburg

Angemeldet 


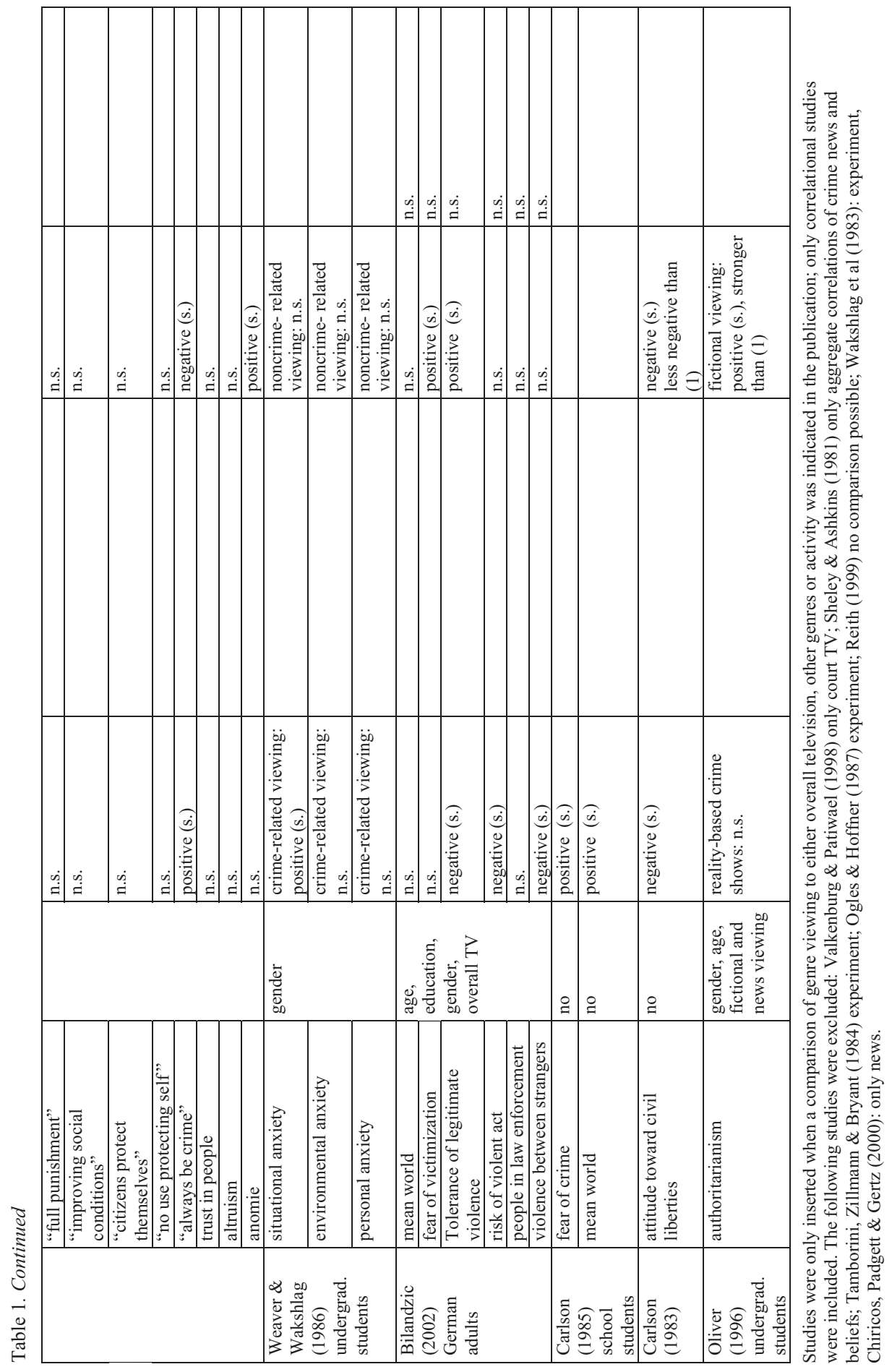

Bereitgestellt von | Universitaetsbibliothek Augsburg

Angemeldet 


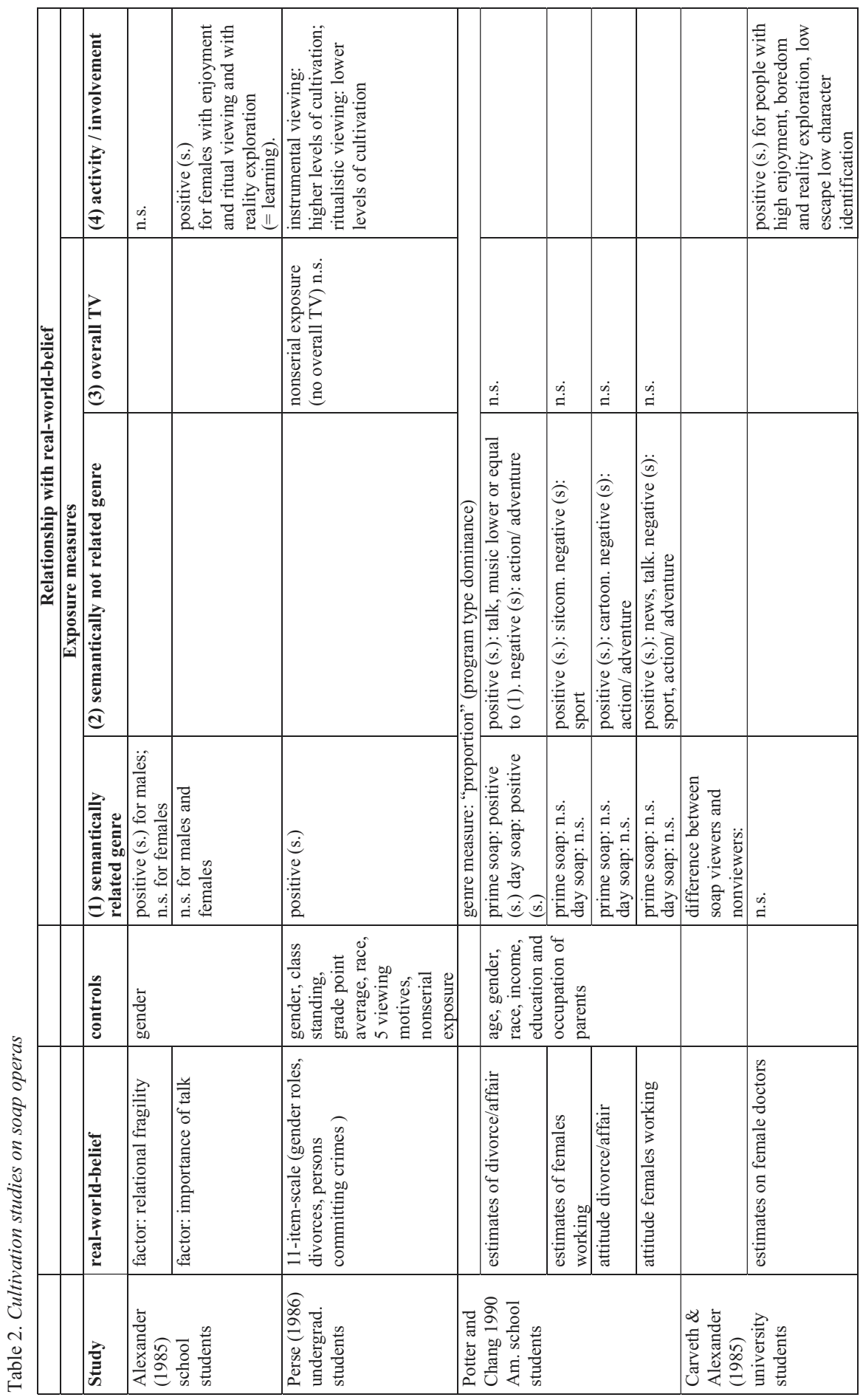

Bereitgestellt von | Universitaetsbibliothek Augsburg Angemeldet 


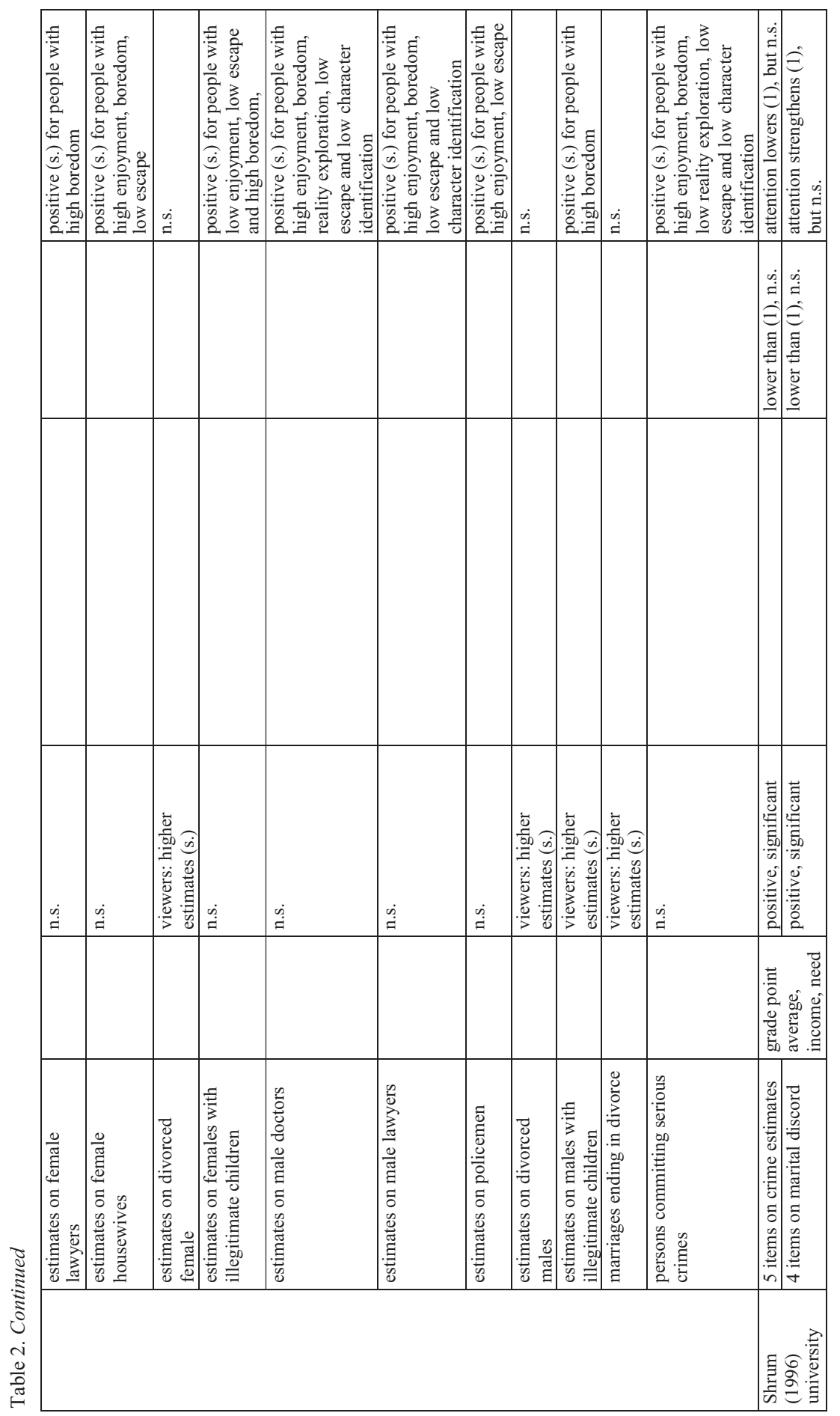

Bereitgestellt von | Universitaetsbibliothek Augsburg 

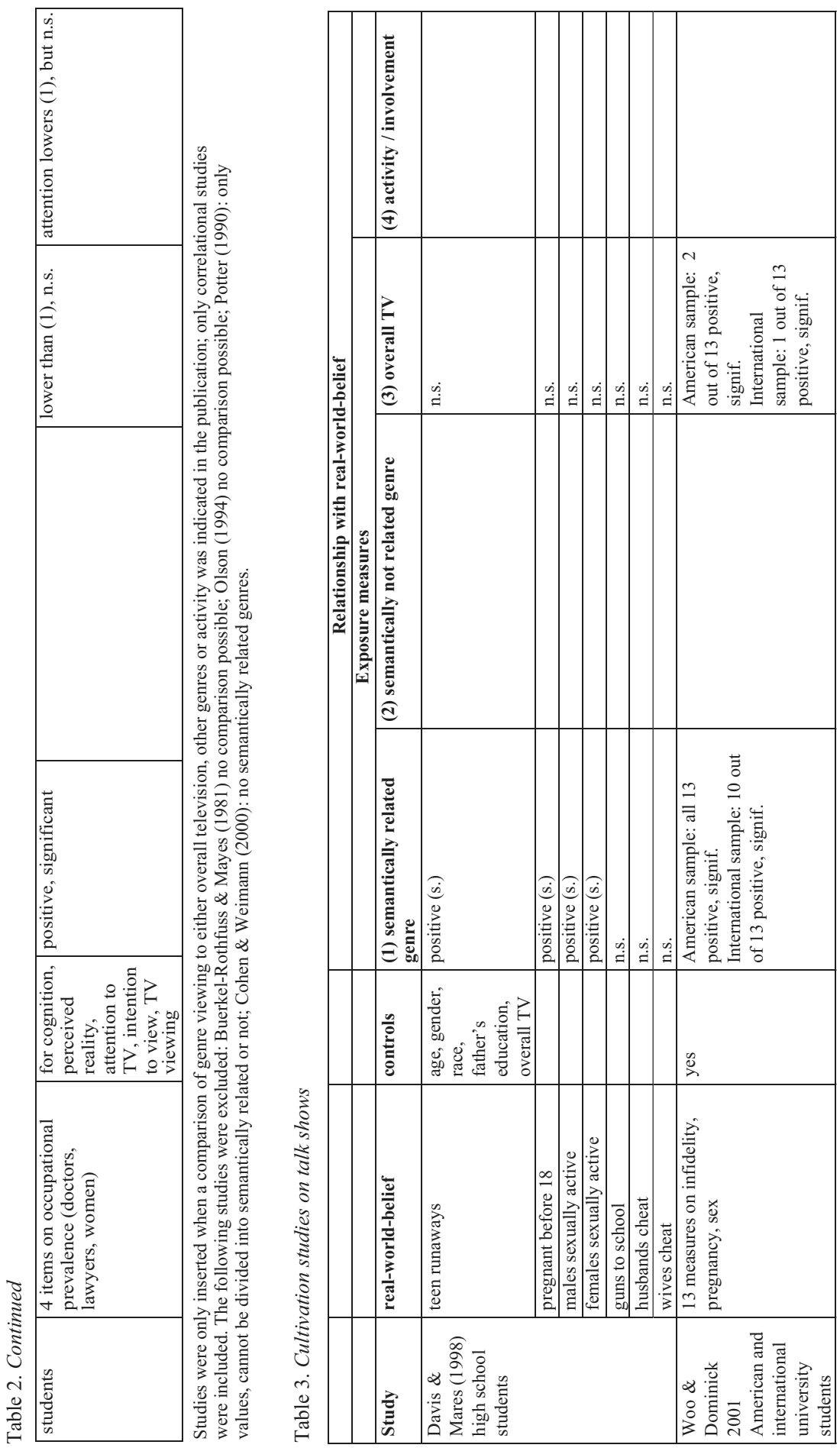

Bereitgestellt von | Universitaetsbibliothek Augsburg

Angemeldet 


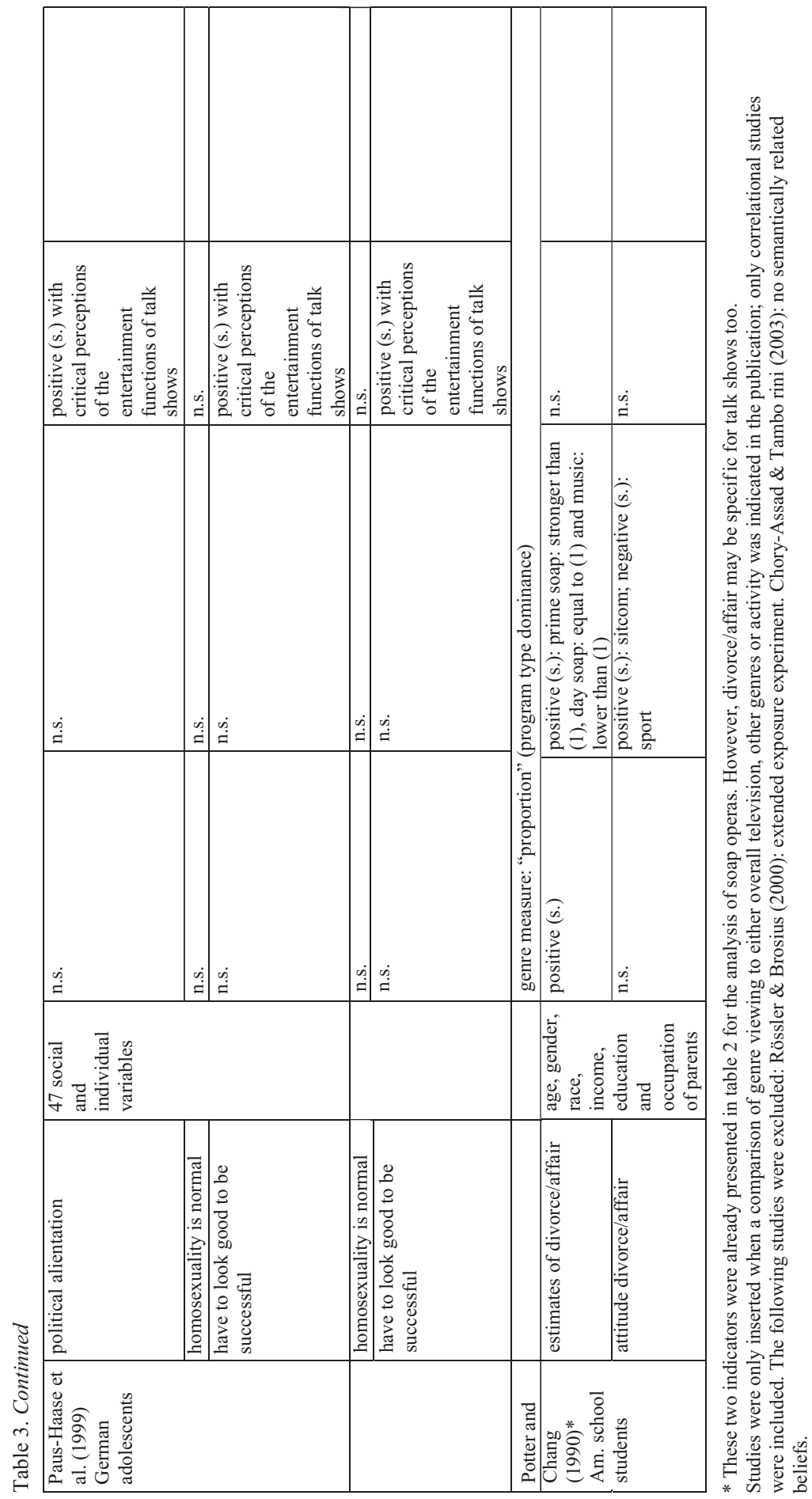

Bereitgestellt von | Universitaetsbibliothek Augsburg 
genre. Thus a second question emerges from the research review presented above: (2) How do television world facts enter the knowledge about the real world?

Finally, results on crime drama suggest a reverse causality as it has already been proposed in early cultivation research (e.g., Doob and McDonald, 1979). People who are fearful and believe in a violent world spend more time in their homes and spend this time watching television. They, however, try to avoid crime-related content (i. e., crime drama) and look for crime-free content (e. g., soap operas, music, game shows). Obviously, reverse causality does not need to be assumed for other genres. Thus, another theoretical question arises: (3) How can both patterns of causality be integrated into the cultivation paradigm?

The next section elaborates on the three questions that have arisen in our research review and it offers additional evidence from a broader set of literature. We will develop a model that may explain some of the gaps in cultivation theory identified above.

\section{Consequences for theorizing in cultivation research}

\section{(1) What part of the television message does actually influence the viewer? Meta-narratives as the cultivating message}

The numerous operationalizations of cultural indicators point to the fact that there are obviously many messages inherent in one television stimulus. Crime drama, for example, portrays a specific case, but at the same time offers depictions of men and women as victims and perpetrators, shows the victory of good over evil, or characterizes the detective in a certain stereotypical way. So, what is the message that enters the viewer's mind? Sometimes, research sticks to the presented facts: The crime rate, age and gender of victims or professionals. On the other hand, if you try to recount the story of a crime drama, would you use these aspects? Probably not; you would rather use the main point of the narration to describe it. Without neglecting incidental learning, we arrive at an alternative scholarly position to determine what cultivates the viewer. Zillmann (1980) states that the television world is distorted towards safety rather than towards danger, because criminals usually are caught in the television world, and law and order are restored.

In a similar manner, Potter (1990) maintains that people learn more general messages from television and not singular facts. Accordingly, in an empirical study he uses general values like 'Truth always wins out' or 'Hard work yields reward' instead of typical cultivation measures. So the relevant message of crime drama may not be marked by the violence rate, but by the morale underlying crime stories. Potter (1993: 597) calls such general messages of the television metanarratives and assumes that 
perhaps "the mean and violent world is a subset of a more general metanarrative" (for a similar concept see Vlasic, in press). Meta-narratives lie at the base of the actual story and are not confined to a certain show or a certain genre, but cross these borders liberally. Following this rationale, genres cease to be relevant categories of content. It is, for instance, conceivable that crime drama and situation comedy share the same meta-narrative, e.g., 'no matter what problems occur, everything will turn out just fine'. In this case, traditional genre categories would be the wrong indicators for television use; instead, we should start looking for programs sharing similar meta-narratives, and cluster them in metaunits. Nonetheless, questionnaires may still include traditional program categories like single programs or genres, because they represent familiar categories to the respondents. But in data analysis, the independent variable should appear as meta-unit characterized by the same underlying meta-narrative.

Thus, the question raised by Newcomb (1978), concerning the actual meaning of a message to television viewers, should not be regarded as 'irrelevant' or 'distracting' (Gerbner and Gross, 1979) as long as analysis focuses on large commonalities and not on small differences. Shared interpretations of the world outside (Lippman, 1922) supply the grounds for society itself, for the construction of social reality. Whether cultivation research should adopt a recipient-oriented view on cultural indicators or not, is not a matter of shifting levels from the social to the psychological (Morgan and Shanahan, 1997), but a matter of abandoning the normative definition of reality in favor of an actor-oriented perspective. This perspective is, by the way, widely accepted in sociology ever since the Thomas theorem was set up nearly 80 years ago (Thomas and Thomas, 1928).

While Potter's suggestion to look for a general commonality in the television message relies heavily on the content dimension, Newhagen and Lewenstein (1992) suggest that formal features (such as fast pacing, rapid scene changes and salient pictures) might account for the similarities in the cultivation effects of different genres that vary in respect to content. This notion seems to be an interesting idea as it could explain the intensity of learning, even though what is learned is still the content accompanied by the formal features. As formal and salient features are known to evoke attention (e.g., Lang, 2000), this obviously represents the stimulus-driven counterpart of activity or involvement. Likewise, vividness as an attribute of many television portrayals is discussed as an influence on cultivation (Shrum, 1996; Shrum and O'Guinn, 1993; Bilandzic, 2002). So the mode of the presentation may represent a second genre-crossing dimension that influences encoding and storage.

We can specify the basic model of cultivation (Figure 1) and substitute the term genre with the concept of meta-unit (Figure 2). 


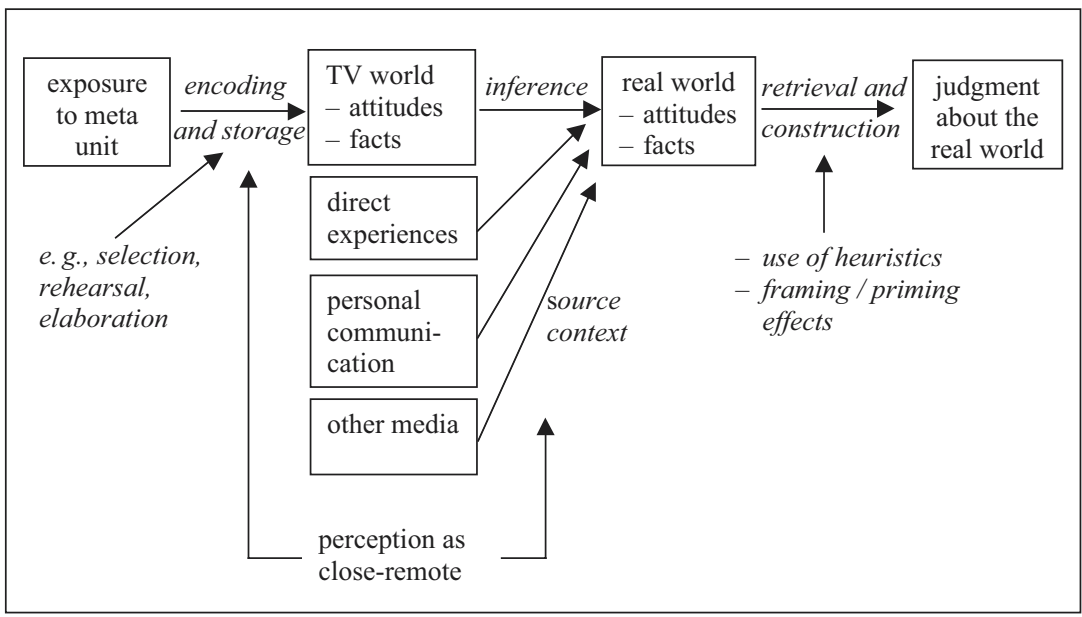

Figure 2. Extended model of the cultivation process

(2) How do television facts enter the knowledge about the real world? The process of inference

Early cultivation research already proposed that there has to be an inferential process where facts from the television world are transferred into real world knowledge. Hawkins, Pingree, and Adler (1987) further investigated this aspect in one adult and three adolescent samples and found that perceptions about the television world were not linked to beliefs about the real world. Consequently, the researchers rejected learning as a necessary process and instead proposed reinforcement processes. Similarly, Potter (1988) examined the correlation between beliefs about the television world and beliefs about the real world. He found a positive relationship between estimates of violent acts on television with the sense of victimization, but not with estimates of violent acts in the real world. This indicates that learning from television facts may impact attitudes (second-order-effects), but not factual knowledge (first-order-effects; Hawkins and Pingree, 1990). Considering these somewhat ambiguous results on inference, learning should not be ruled out but may be conceived as a process that occurs in certain situations for a certain type of belief; in other situations and with other beliefs, though, reinforcement or another process may be crucial.

Another important aspect is the impact of inference-making abilities, estimated by measures of IQ or academic achievement. Pingree (1983) found that cultivation effects were stronger in a group of children that had low inference-making abilities compared to those with high infer- 
ence-making abilities. Testing for genre-specific effects, some relationships previously established with total television viewing vanished, others appeared. Splitting the sample into groups of high and low inferencemaking abilities, children with lower inference-making abilities are more impacted by viewing the genres. This could be interpreted as an uncritical reception of media information; in contrast, people with higher cognitive abilities may just discard television information as not being appropriate for reality judgments - exactly because they have better mental resources. Studies that report viewer activity to weaken cultivation effects point into the same direction. Inference, thus, seems to depend on additional conditions.

If we argue that a process of inference from television knowledge on real world knowledge should exist, then we expect viewers to notice and remember differences between the two kinds of information. This idea is already theoretically elaborated in the multiple trace model that states that events are stored as independent memory traces containing context information, that is, source characteristics (Hintzman and Block, 1971; Shapiro, 1991; Shapiro and Lang, 1991). Thus, each individual experience is encoded along with the information where this experience was acquired, for example, in fictional television programs or news, in the newspaper, from a friend, or in a direct experience. This contextual information is used to assess whether a memory trace is suitable for a realworld judgment or not.

But how can information from fictional television be used for realworld judgments? Two possibilities exist; first, the fictional source is forgotten and the information is used anyway. Second, the fictional source does not matter, because what is learned applies to both television and real world.

In the first case, people do learn and remember fictional television information, but do not take source characteristics into account (Shrum, 1995) or confuse sources (Mares, 1996) when making a judgment. And this may happen easily, because source information decays more quickly than the actual information itself - a phenomenon that is closely related to the sleeper-effect (Pratkanis et al., 1988). If, on the other hand, people remember the fictional source, they tend to discount the information, for example, when primed to think of television as a possible source of real-world-beliefs (e.g., Shrum, Wyer, and O'Guinn, 1998). Shrum (1995) emphasizes the importance of viewer involvement for source retention or decay. Low involvement or 'passive' viewing leads to superficial processing of both information and source characteristics. As source information is forgotten more quickly than the actual information, less involved viewers are more likely to use television information to con- 
struct their judgments. This might account for the counterintuitive results on activity presented above.

People construct their social reality from many sources, such as reallife experiences, interpersonal communication or other media (e. g., Adoni and Mane, 1984; Cohen, Adoni, and Drori, 1983; Doob and McDonald, 1979). Furthermore, it is plausible that viewers do not treat all information equally, but find some bits more adequate than others for real-world judgments. Context seems to be a crucial factor in cultivation. Thus, we include 'source context' as a factor into our model of the cultivation process (Figure 2).

The second possibility why people may use information from fictional television for real-world-judgments is that the messages they learn are so general in nature that source does not matter. This, of course, would apply especially to the effect on attitudes (second-order-effects; Hawkins and Pingree, 1990). Shapiro and Lang (1991: 687) propose that people use "on-line evaluation of the message to modify attitudes toward some object or idea", for example, in the sense of dual-process theories like the Elaboration-Likelihood Model by Petty and Cacioppo (1981). Such a notion of the cultivation process fits perfectly with the concept of meta-narratives that provide such non-factual information. Hawkins and Pingree (1990: 45), in a similar manner, propose that divergent processes may account for first- and second-order-effects, the information influencing the latter being processed immediately and "reinforcing or changing [...] already-existing social reality beliefs" (see also Hawkins, Pingree, and Adler, 1987).

Pre-existing attitudes have not been a matter of great concern in cultivation research - yet they seem crucial because people have their own history of experiences, knowledge and attitudes that serve as background for new experiences. Adoni and Mane (1984) have phrased this idea more generally, building on the sociology of knowledge by Berger and Luckmann (1967) and Schütz (1967). They propose that our knowledge of the world is composed of individual and subjective beliefs and perceptions, constituting subjective social reality in a "dialectical process in which human beings act both as the creators and as products of their social world" (Adoni and Mane, 1984: 325). Subjective reality is organized in 'zones of relevance' meaning that elements of knowledge have different distances to everyday life of the individual. These elements are situated on a continuum ranging from very close to very remote. Faceto-face-experiences, for example, are very close, phenomena like public opinion seem very remote. This bears an important implication for the cultivation process. Information that is perceived to be close might be more easily integrated into one's knowledge or attitudes, and information that is perceived to be remote might be even ignored because the 
individual cannot see connections to his or her personal life. This idea obviously connects to the resonance concept by Gerbner and his associates (e. g., 1994) and to the concepts of involvement and activity, but it is theoretically situated at a more general level.

The close-remote-distinction thus might explain differences in effects of various cultural indicators. People may perceive violence in crime drama as very remote, because they never witnessed something like it, but might feel very close to soap operas, because relationships and everyday problems are similar to their own lives. Again, the limitation of genre as a relevant structural unit of television becomes apparent as the close-remote distinction cuts across genres. Elements from fictional fantasy programs may be much closer to a viewer as they portray a human conflict the viewer him- or herself struggles with. In contrast, elements of reality-based television news may be perceived as very remote, because a viewer does not attribute personal relevance to a presidential election in a foreign country. The close-remote-distinction, too, is integrated into our working model (Figure 2).

\section{(3) How can both patterns of causality be integrated into the cultivation paradigm? Gratificational context}

Our research review indicates that sometimes beliefs are not the results, but the motives for exposure. Especially the evidence on crime drama suggests a reverse causal relationship, because the correlation with semantically related beliefs is generally weaker than with overall television - and also weaker than with other, semantically unrelated genres. Although this is not true for every cultivation measure and every genre, it emphasizes the importance of considering motives for television use in the cultivation process (cf. Tapper, 1995). How intertwined motives and effects are, can be assessed with several studies that follow a uses-andgratifications-paradigm while using the very same data set a cultivation researcher would use (e.g., Oliver and Armstrong, 1995; Minnebo, 2000). However, there is no reason to dismiss one causal hypothesis in favor of the other. In a natural long-term process like cultivation, people regularly turn to television to satisfy their needs, and, in turn, get some of their needs actually satisfied, and, in addition, unintended effects (like knowledge or beliefs they have not sought after). Apart from these unintended effects, this notion corresponds with the classical Uses-and-Gratification model that distinguishes between gratifications sought and obtained (Palmgreen and Rayburn, 1982). Effects, whether intended or not, can only occur when exposure is allowed for by the viewer. 
If people have some control over what they watch, and approach television with certain expectations, the mode of processing television messages should differ according to the motives and expectations in different situations. It should matter, for instance, whether people watch crime shows to be entertained, because they like an actor, or they like the humor of a show, or in order to learn about prevention of crime and to learn what to do if they are assaulted. The mode of decision can be plausibly connected to the mode of processing. When a decision is made rationally, the stimulus has to be considered carefully in order to find out whether it is useful for gratifications sought. When one decides habitually what to watch, cognitive activity might be low and the television stimulus might be processed less intensely.

Thus, the gratifications sought might change the nature of learning from television, like Potter (1988: 938) proposes: "[A]dolescents who concentrate on viewing news programs should be expected to learn more about current events [...] But when adolescents view TV for entertainment purposes, it is much less reasonable to hold an expectation that greater exposure would lead to greater amounts of learning".

Accordingly, the gratificational context of acquiring beliefs from television seems crucial to modeling cultivation effects. Gratifications are much more than intervening variables; rather, they constitute and shape the process that enables effects. Thus, we should stop thinking about cultivation as an effect and start thinking of it as a reciprocal process of recipient and television message. Atkin, Greenberg, and McDermott (1983: 414) already suggested that the "simple stimulus-response learning model" is not an adequate perspective on effects and conclude that "it is the combination of exposure and interpretation that determines impact".

The introduction of gratifications enables us to draw a distinction that may offer further precision to explaining differential effects of genres. In crime drama, for example, criminal deeds are solved, felons are punished and safety is restored - if this is the message a viewer learns from television, we can argue that he or she could have anticipated the message from the genre, and that he or she watched the genre in order to get this message. In contrast, a viewer might watch sitcoms because he or she wants to be amused, but might learn something about race differences. Whether one seeks out an information (GS) and learns it (GO), or looks for an information (GS) and learns something else incidentally, might make a great difference - not only in outcome, but also in the processes that lead to learning (i. e., intentional learning versus incidental learning). This, in turn, might involve specific intervening variables, for example, it is conceivable that activity only enhances intentional learning, but not incidental learning. It is remarkable that many of the classic cultiva- 
tion indicators are most certainly not elements viewers typically seek, for example, knowledge about frequency of violence or divorce; or demographic characteristics of television characters.

Several studies have already investigated the influence of viewing motives on cultivation effects. Carveth and Alexander (1985) found out that cultivation effects are stronger when viewers watch soap operas with ritualistic motives and weaker when they watch with instrumental motives like reality exploration or identification with television persons. Several other scholars have confirmed that active viewing can have an inhibiting effect (Rouner, 1984; Pingree, Starrett, and Hawkins, 1981). Bilandzic (2002) found neither an effect of activity nor of involvement in crime drama viewing. Two studies, however, found a reinforcement effect of active, instrumental viewing on cultivation; one study found it for soap opera viewing (Perse, 1986), the other for court TV (Valkenburg and Patiwael, 1998). The results are somewhat mixed and might indicate different effects and processes according to genres and beliefs.

So far, we have considered the consequences of the gratificational context for learning only. Other results suggest that we might have to broaden our views on gratifications and cultivation. Zillmann and Wakshlag (1985) found that crime drama actually reduces fear of victimization. Instead of learning the information, apprehensive viewers might instantly use it only to lower their fears. By integrating gratifications sought and obtained into the basic model of cultivation, we finish the development of our model in Figure 3.

\section{An integrated view: The Gratification/Cultivation model}

Summing up, the process of cultivation starts with the gratifications a viewer wants to obtain from television (Figure 3). The gratifications sought from television lead to the exposure to a meta-unit - which represents a latent structure in television content that covers programs with similar meta-narratives. Meta-units are not congruent with genre structure. Thematically similar genres like crime drama and real-life police shows may bear very different meta-narratives (like 'the world is a safe place' versus 'the innocent are those to get killed') and very different genres may include similar meta-narratives, like comedy and crime drama ('no matter what happens, everything will turn out fine').

Exposure, in turn, eventually results in gratifications obtained. Both forms of gratification must be seen as processes. Gratifications sought are not static, but dynamic conditions that change during exposure, for example, when a viewer has the motive to learn about a specific news topic, and eventually, feels she has been sufficiently informed and turns to a film in order to be entertained. Similarly, gratifications obtained do 


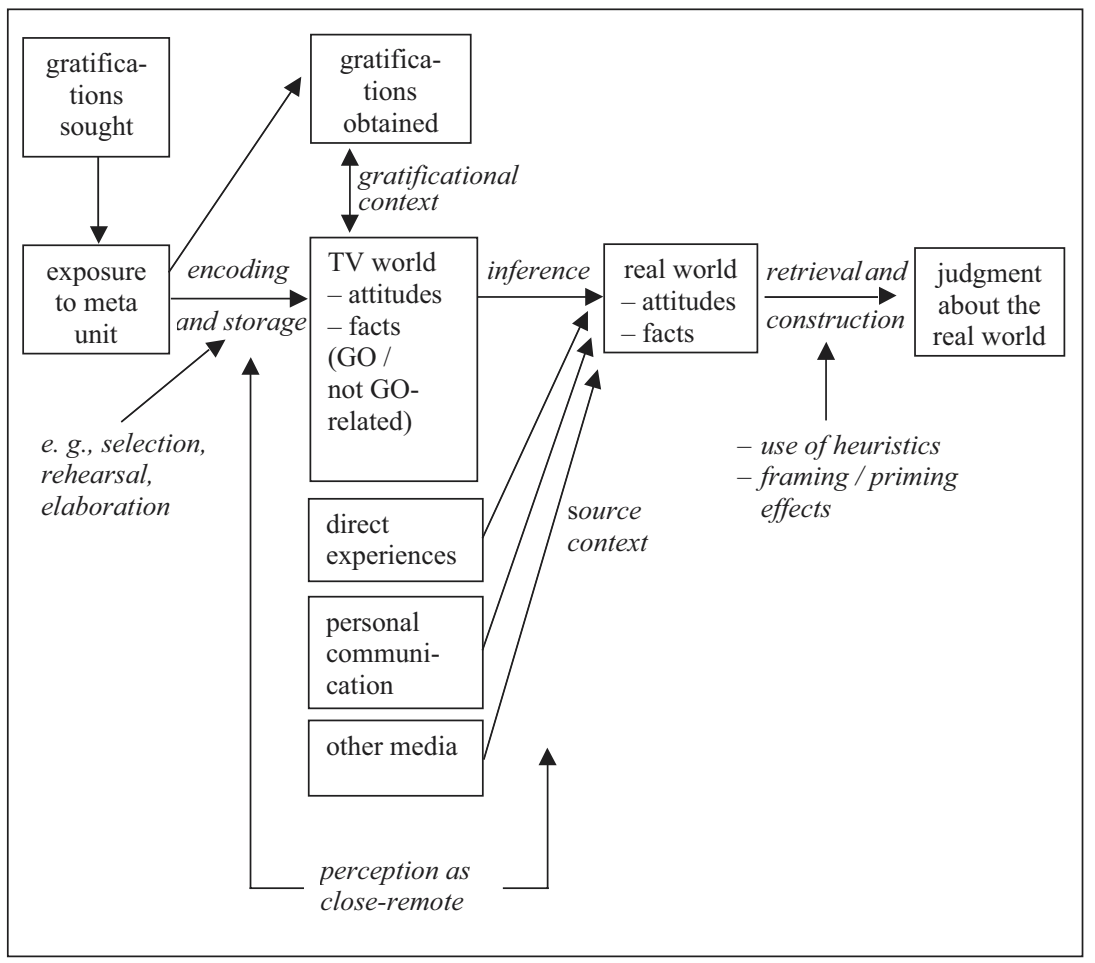

Figure 3. The Gratification/Cultivation model

not suddenly emerge at the end of the exposure, but arise and change during exposure, for example, when a viewer actually feels entertained or learns something about the news item. Gratifications obtained represent the gratificational context in which bits of television information are processed and learned.

As cultivation is often seen in the context of ritual or habitual viewing (Gerbner et al., 1979, 1994), we should elaborate on the compatibility of television viewing seen as a rational, gratification-lead action and habitual behavior that is usually seen as passive and devoid of reflection on motives and goals. Habits play an important role in human action, because they relieve people of the complex and effortful process of pondering every action in respect to the possible positive or negative consequences. Esser (1990) states that - even in rational theory which uses and gratifications are an example of - excessive deliberation and search for additional information is not rational, because the costs of this process in terms of time and effort are not justified by their additional use. 
Nonetheless, habits build on repeated, deliberate choices; if an action repeatedly meets expectations, an action may be carried out without explicit deliberation. Similarly, Rosenstein and Grant (1997) propose that habits start when people use media with certain motives. Repeated (rewarded) exposure results in scripts storing certain action patterns that guide habitual media use - in this sense, habits are strategies for carrying out everyday activities quickly and effortlessly. Conceptualizing habits as reasonable strategies for coping with a bulk of information makes them compatible with rational theories of human action (Esser, 1990).

Gratificational context may impact on this processing and learning in several ways. First, it is important whether information is related to gratifications sought or not, for example, whether a viewer learns something he or she intended to learn or learns something incidentally while seeking something else. Second, gratificational context may be treated as information of its own and be encoded along with the actual bit of television information, in the same way as source characteristics (see Shapiro and Lang, 1991). This information may be influential for integrating TV beliefs in real world beliefs and the construction of judgments, for example, information acquired while being entertained might be discounted as not suitable for a judgment on the real world.

A similar process has been discussed for source characteristics. If an information is remembered to come from a fictional source, it is discounted from the judgment (Shrum, 1995). Whether gratificational context is an additional factor or even more influential than source characteristics, is an empirical question. In addition to television information, people have many other sources for their beliefs; most importantly, direct experiences, but also personal communication and other media experiences. Along with information from each source, the source context is stored in memory which is later used to evaluate the veracity and usefulness of a bit of information for a real-world judgment.

Eventually, beliefs from TV world are integrated into real world beliefs. What is still rather unclear, is when integration takes place: Is it integrated during exposure, or in the moment a person has to construct a real-world-judgment (cf. Van den Bulck, 2003)? In the latter case, the processes of integration and construction occur at the same time. But this, too, is an empirical question.

Both learning and integration are influenced by the perception of an information as close or remote. It may well be possible that this perception determines whether an information is learned or not, whether it is integrated into the real-world beliefs during reception or when constructing the judgment and thus alter cultivation effects altogether. 
The last process in the model is different from the gratification-exposure and the encoding-storage process which represent long-term, enduring processes. Construction, in contrast, is short-term in that it occurs at certain points in time, for example, when a person is asked for a judgment in a cultivation survey. Whether this is the only occasion for construction to occur, making cultivation an artifact of research, is not clear (Shrum, 1995). This again may depend on the questions asked. It is conceivable, for example, that people normally do not at all think about statistical distributions or communicate about such matters, but they might well be thinking about attitudes perceived in television. Cultivation judgments then, like any other judgments, can be influenced by (1) priming of certain sources, by (2) framing the judgmental problem with a symbolic frame, and by (3) decision heuristics making the process quick and effortless.

Describing the process as a whole, the Gratification/Cultivation model represents a heuristic for further research. Certain parts have still to be substantiated with additional assumptions from theories of information processing, reality construction and decision making, and with exploratory research on other parts where no such theories exist. The model integrates situational and dynamic aspects like the development of gratifications during exposure, and the perception of closeness on the one hand, and aspects detached from actual reception situations, like integrating the acquired information into one world view, on the other hand. A third level is introduced with construction that (for some parts) may occur only in survey situations. These three levels have to be related to each other in empirical research. Micro-level cognitive processing and its interaction with long-term consequences will have to be investigated. In this sense, the model may imply a new direction in cultivation research. Five major research orientations are suggested by the model:

\section{Finding the meta-narratives}

Obviously, the crucial point in researching cultivation is to find the accurate message, maybe even multiple accurate messages, that are assumed to exert a cultivating influence. It has often been argued by cultural studies scholars that texts do have multiple meanings, and readings of them can differ individually (Livingstone, 1980; Newcomb, 1978), but considering the common background of culture and society, the essence will probably be shared among members of society or at least among social groups. In general, there will be a preferred reading and some consensus about what a text says (Hall, 1980). This notion stems theoretically from a similar critical background like cultivation analysis. Yet it is surprising that virtually none of the methodological and methodical 
foundations of cultural studies have entered cultivation research. Trying to find the meta-narrative may be a good occasion to start, because conventional content analytic procedures will not be helpful. Rather than single features of the program, such as violent acts or demographic characteristics of television persons, meta-narratives represent complex semantic structures.

Potter's (1990) 'primary values' serve as an example what meta-narratives may look like (e. g., 'Truth always wins out' or 'Hard work yields reward'). What makes them particularly difficult to analyze is that they can emerge on very different levels of the program, in a single scene, after the introduction or even only at the end of the program. As a consequence, not only a range of possible messages has to be found, but the level of abstraction must also be determined. Borrowing from cultural studies, qualitative reception analysis may be a suitable strategy of investigating meta-narratives. A two-fold procedure seems appropriate. First, a range of programs is selected that represents typical exemplars of television genres. Second, the programs are shown to different persons and give the impulse for a focus group discussion or a qualitative one-onone interview. The goal is to find out what basic message people perceive in the programs.

Of course, a recipient-oriented approach has limitations in two respects. First, it will not be possible to explore the whole range of genres in this way, because the qualitative procedures are very time-consuming and costly. Second, we must consider the possibility that people may not be able to identify and verbalize the relevant messages. Thus a combination of recipient-oriented procedures with textual analysis seems appropriate. Qualitative methods such as narrative analysis (which has already been used for a long time in linguistics for in-depth-analysis of narrations and their fundamental value systems (e.g., Greimas, 1983; Manning and Cullum-Swan, 1994)) may be useful. Meta-narratives thus found can be used to cluster genres or single programs into similar metaunits. This two-fold procedure consisting of normative and recipientoriented methods allows for a comparison of meta-narratives that people can recognize on their own and those they are not able to identify.

\section{Interaction of gratifications sought and obtained with exposure and learning}

The role of gratificational activity is ambiguous. It may enhance learning, but it may also enhance learning of source characteristics only and inhibit inferences. Furthermore, the motivation to learn may result in a good learning of a particular element, but to the detriment of others. We already elaborated on the dynamic notion of gratifications that can 
emerge and change during reception. This again requires research on the micro-level of reception processes. Possible research designs could consist of showing viewers selected programs and, during reception, map the gratifications a viewer seeks and obtains. This can be achieved by means of short quantitative questionnaires that have to be filled out at selected points in time (Scherer and Schlütz, 2002). A qualitative approach seems reasonable as well. Think-aloud procedures asking people to continually verbalize their thoughts throughout reception, or thoughtlisting techniques that (again at selected points in time) ask people to verbalize or write down their current thoughts (Ericsson and Simon, 1993) are often used methods. Gratifications that emerge from the protocols can be related to cultivation questions, preferably consisting of the meta-narratives identified in the first step.

\section{Perception of an information as close or remote}

Once more, the analysis of actual reception situations seems indispensable. In a possible research design focusing on this question, viewers may be confronted with a variety of programs that represent typical instances of the television world that builds on the meta-narratives found out earlier. Apart from a direct evaluation of how close or remote a particular element is perceived by the respondents, a more indirect approach may be advised. Here again, we can work with the process-oriented thinkaloud procedure or thought-listing, and from there make systematic inferences (e.g., with content analysis) about closeness. The goal of this time-consuming procedure must be to find more stable indicators predicting perception of closeness independently of the actual reception situation.

\section{Interaction of the close-remote distinction with encoding-storing and inference}

Close information may be learned and integrated more easily than remote information, or learned through a different process, for example, intentional instead of incidental learning. Here, a possible research design can be combined with the previous step. First, respondents evaluate the closeness of various bits of television information that have been selected before as typical pieces representing a wide range of television messages. Then, in a separate part, respondents are delivered a cultivation questionnaire about their beliefs on (1) the television world and (2) the real world. The beliefs have to be semantically related to the television samples respondents have seen before. Thus, we can analyze whether beliefs from the semantic field of a 'close' information are 
stronger than 'remote beliefs'. Yet, the important point is that the evaluation of closeness has to be treated as an indicator how typical television messages are perceived. The subsequent cultivation questions do not collect data on how well the information given in the first part of the study is learned, but on general beliefs about the television and real world. Otherwise, it would test simple short-time learning and not cultivation.

\section{Interaction of gratifications sought and obtained with the close-remote distinction and judgment making}

Does a certain constellation of gratifications and perception of closeness promote a certain judgment? Here again, we have to combine perceptions of television messages and the gratifications during actual reception situations with beliefs on a general level. In contrast to the previous designs proposed, this one has to deal with short-term effects on judgments and needs to investigate how, for example, priming effects interact with gratifications and perceptions.

\section{Conclusions}

Like many other scholars who promote content-specific cultivation research, we have started out by criticizing the two assumptions by Gerbner about homogeneity of television content and non-selective viewing. Following the analysis of genre-specific effects and the development of the Gratification/Cultivation model, we shall now reconsider these two assumptions as both are in a way implied by our model, though in a clearly modified meaning.

Homogeneity of television content can easily be refuted when simple factual (traditional) indicators are considered, like acts of violence, professional roles or gender of television persons. Such indicators do vary across genres and even across individual shows. But on the other hand, the idea that there are "subtle commonalities underlying superficially different program types" (Morgan and Shanahan, 1997: 6) is striking; it, however, does not work with factual, singular indicators. Meta-narratives, in contrast, explicitly build on this idea of underlying messages that are deeply built into television narratives - and may represent a possibility of saving the homogeneity idea.

The second assumption of non-selectivity may not be sustainable if the mere selection of programs is considered. People do choose genres and programs according to their preferences; while most of television viewing may be habitual, viewing patterns are not erratic, but have developed over a long period of time and in accordance with individual preferences. Yet a different aspect of activity may be much more important 
than mere selection. The gratifications a viewer seeks and obtains can imply active viewing (e.g., motivation to learn about a topic) or less active viewing (e.g., motivation to relax) and, in turn, influence subsequent processes of learning and integration. Activity can vary with television content and in different situations. Therefore, activity should not be conceptualized as a prerequisite, but as a factor.

Introducing motivational aspects in a model of cultivation is a more radical modification of the traditional causal hypothesis than it may seem at first sight. It implies that investigating reality constructions of people must start from the individual, from subjective interpretations and motivations, and from the use and relevance of television information in daily life - rather than isolating television use as a single factor. Only then will we be able to determine the part played by television (among many other sources of reality construction). Such a shift in perspective may explain why some people do not seem to be affected by a huge amount of television viewing while others are affected by viewing only occasionally.

Hawkins and Pingree (1990: 35-36) maintain that without explaining the psychological processes, "cultivation runs the risk of being dismissed as a label for a single correlate" and "as long as these effects occur within a 'black box,' the whole enterprise remains vulnerable to questions of spuriousness". Rather than establishing the mere relationship between television viewing and beliefs, it seems indispensable to test further assumptions about the hypothesized processes between viewing and the expression of a belief. To achieve this goal, it may even be useful to set up an alternative explanation of cultivation and test two alternative sets of hypotheses. One set that describes the empirical situation if television is involved in the processes and one that describes the empirical situation if third variables are at work. It is crucial to give cultivation theory a genuine chance to be falsified - which is clearly not true when investigating a single relationship.

\section{References}

Adoni, H. and Mane, S. (1984). Media and the social construction of reality. Toward an integration of theory and research. Communication Research, 11(3), 323-340.

Alexander, A. (1985). Adolescents' soap opera viewing and relationale perceptions. Journal of Broadcasting and Electronic Media, 29, 295-308.

Atkin, C. K., Greenberg, B. S., and McDermott, S. (1983). Television and race role socialization. Journalism Quarterly, 60(3), 407-414.

Bandura, A. (1977). Social learning theory. New York: General Learning Press.

Berger, L. P. and Luckmann, T. (1967). The social construction of reality. New York: Anchor Books.

Bilandzic, H. (2002). Genrespezifische Kultivierung durch Krimirezeption. Medienpsychologie, 14(2), 60-68. 
Buerkel-Rothfuss, N. L. and Mayes, S. (1981). Soap opera viewing: The cultivation effect. Journal of Communication, 31(3), 108-115.

Busselle, R. W. (2001). Television exposure, perceived realism, and exemplar accessibility in the social judgment process. Media Psychology, 3(1), 43-67.

Carlson, J. M. (1983). Crime show viewing by preadults: The impact on attitudes toward civil liberties. Communication Research, 10(4), 529-552.

Carlson, J. M. (1985). Prime time law enforcement: Crime show viewing and attitudes toward the criminal justice system. New York: Praeger.

Carveth, R. and Alexander, A. (1985). Soap opera viewing motivations and the cultivation process. Journal of Broadcasting and Electronic Media, 29(3), 259-273.

Chiricos, T., Padgett, K., and Gertz, M. (2000). Fear, TV news, and the reality of crime. Criminology, 38(3), 755-785.

Chory-Assad, R. M. and Tamborini, R. (2003). Television exposure and the public's perceptions of physicians. Journal of Broadcasting and Electronic Media, 47(2), $197-215$.

Cohen, A. A., Adoni, H., and Drori, G. (1983). Differential perceptions of social conflicts in social reality and television news. Human Communication Research, $\frac{10,203}{22} 5$.

Davis, S. and Mares, M.-L. (1998). Effects of talk show viewing on adolescents. Journal of Communication, 48(3), 69-86.

Doob, A. N. and Macdonald, G. E. (1979). Television viewing and fear of victimization: Is the relationship causal? Journal of Personality and Social Psychology, 37, 170-179.

Ericsson, K. A. and Simon, H. A. (1993). Protocol analysis: Verbal reports as data. Cambridge: Cambridge University Press.

Esser, H. (1990). Habits, Frames und Rational Choice: Die Reichweite von Theorien der rationalen Wahl. Zeitschrift für Soziologie, 19(4), 231-247.

Esser, H. (1999). Soziologie. Spezielle Grundlagen. Band 1: Situationslogik. Frankfurt: Campus.

Gehrau, V. (2001). Fernsehgenres und Fernsehgattungen. Ansätze und Daten zur Rezeption, Klassifikation und Bezeichnung von Fernsehprogrammen. München: Fischer.

Gerber, G. and Gross, L. (1979). Editorial response: A reply to Newcomb's 'humanistic critique'. Communication Research, 6, 223-230.

Gerbner, G. and Gross, L. (1976). Living with television: The violence profile. Journal of Communication, 26(2), 173-199.

Gerbner, G., Gross, L., Jackson-Beeck, M., Jeffries-Foy, S., and Signorielli, N. (1978). Cultural indicators: The violence profile no. 9. Journal of Communication, 28(3), 176-207.

Gerbner, G., Gross, L., Morgan, M., Signorielli, N., and Jackson-Beeck, M. (1979). The demonstration of power: Violence profile no. 10. Journal of Communication, 29, 177-196.

Gerbner, G., Gross, L., Morgan, M., and Signorielli, N. (1994). Growing up with television: The cultivation perspective. In J. Bryant and D. Zillman (Eds.), Media effects: Advances in theory and research (pp. 17-41). New Jersey: Lawrence Erlbaum.

Greenberg, B. S., Edison, N., Korzenny, F., Fernandez-Collado, C., and Atkin, C. K. (1980). Antisocial and prosocial behavoirs on television. In B. S. Greenberg (Eds.), Life on television: Content analyses of US TV drama. Norwood, NJ: Ablex Publishing Company..

Greimas, A. J. (1983). Structural semantics. An attempt at a method. Lincoln: University of Nebraska Press.

Hall, S. (1980). Encoding/Decoding. In S. Hall and D. Hobson (Eds.), Culture, media, language (pp. 128-138). London: Hutchinson. 
Hawkins, R. and Pingree, S. (1980). Some processes in the cultivation effect. Communication Research, 7(2), 193-226.

Hawkins, R. and Pingree, S. (1981a). Uniform messages and habitual viewing: Unnecessary assumptions in social reality effects. Human Communication Research, 7(4), $291-301$.

Hawkins, R. and Pingree, S. (1981b). Using television to construct social reality. Journal of Broadcasting, 25(4), 347-364.

Hawkins, R. and Pingree, S. (1982). Television's influence on social reality. In D. Pearl, L. Bouthilet, and J. Lazar (Eds.), Television and behavior: Ten years of scientific progress and implications for the Eighties (pp. 224-247). Washington, DC: Government Printing Office.

Hawkins, R. and Pingree, S. (1990). Divergent psychological processes in constructing social reality from mass media content. In N. Signorielli and M. Morgan (Eds.), Cultivation analysis: New directions in media effects research (pp. 35-50). Newbury Park, CA: Sage.

Hawkins, R., Pingree, S., and Adler, I. (1987). Searching for cognitive processes in the cultivation effect. Adult and adolescent samples in the United States and Australia. Human Communication Research, 13(4), 553-577.

Heeter, C. (1988). The choice process model. In C. Heeter and B. S. Greenberg (Eds.), Cableviewing (pp. 11-32). Norwood, NJ: Ablex.

Hintzman, D. L. and Block, R. A. (1971). Repetition and memory: Evidence for a multiple-trace hypothesis. Journal of Experimental Psychology, 88, 297-306.

Lang, A. (2000). The limited capacity model of mediated message processing. Journal of Communication, 50(1), 46-70.

Lippmann, W. (1922). Public opinion. New York: Harcourt, Brace.

Livingstone, S. (1980). Viewers' interpretations of soap opera characters. In P. Drummond and R. Paterson (Eds.), Television and its audience: International research perspectives. London: BFI.

Manning, P. K. and Cullum-Swan, B. (1994) Narrative, content and semiotic analysis. In N. K. Denzin and Y. S. Lincoln (Eds.), Handbook of qualitative research (pp. 463-477). Thousand Oaks, CA: Sage.

Mares, M.-L. (1996). The role of source confusions in television's cultivation of social reality judgements. Human Communication Research, 23(2), 278-297.

Minnebo, J. (2000). Fear of crime and television use. A uses and gratifications approach. Communications, 25(2), 125-142.

Morgan, M. and Shanahan, J. (1997). Two decades of cultivation research: An appraisal and meta-analysis. In B. R. Burleson and A. W. Kunkel (Eds.), Communication Yearbook 20 (pp. 1-45). Thousand Oaks, CA: Sage.

Newcomb, H. (1978). Assessing the violence profile of Gerbner and Gross: $\underline{A}$ humanistic critique and suggestion. Communication Research, 5, 264-282.

Newhagen, J. E. and Lewensten, M. (1992). Cultivation and exposure to television following the 1989 Loma Prieta Earthquake. Mass Comm Review, 49-56.

Ogles, R. M. and Hoffner, C. (1987). Film violence and perceptions of crime: The cultivation effect. In M. L. McLaughlin (Ed.), Communication Yearbook 10. Beverly Hills, CA: Sage.

O'Keefe, G. J. (1984). Public views on crime: Television exposure and media credibility. In R. N. Bostrom (Ed.), Communication Yearbook 8 (pp. 514-553). Beverly Hills, CA: Sage.

Oliver, M. B. (1996). Influences of authoritarianism and portrayals of race on Caucasian viewers' responses to reality-based crime dramas. Communication Reports, $9(2), 142-150$. 
Oliver, M. B. and Armstrong, G. B. (1995). Predictors of viewing and enjoyment of reality-based and fictional crime shows. Journalism and Mass Communication Quarterly, 72(3), 559-570.

Ormrod, J. E. (Ed.). (1999). Human learning. Upper Saddle River, NJ: Merrill.

Palmgreen, P. and Rayburn, J. (1982). Gratifications sought and media exposure: An expectancy value model. Communication Research, 9, 561-580.

Paus-Haase, I., Hasebrink, U., Mattusch, U., Keuneke, S., and Krotz, F. (1999). Talkshows im Alltag von Jugendlichen. Der tägliche Balanceakt zwischen Orientierung, Amüsement und Ablehnung. Opladen: Leske \& Budrich.

Perse, E. M. (1986). Soap opera viewing patterns of college students and cultivation. Journal of Broadcasting and Electronic Media, 30(2), 175-193.

Petty, R. E. and Cacioppo, J. T. (1981). Attitudes and persuasion: Classic and contemporary approaches. Dubuque: William C. Brown.

Pingree, S., Starrett, S., and Hawkins, R. (1981). Soap opera viewing and social reality. Paper presented to the International Communication Association, Minneapolis.

Pingree, S. (1983). Children's cognitive processes in constructing social reality. Journalism Quarterly, 60(3), 415-422.

Popper, K. R. (1999). The high tide of prophecy: Hegel, Marx, and the aftermath (5th ed., reprinted (1945)). London: Routledge.

Potter, W. J., Warren, R., Vaughan, M., Howley, K., Land, A., and Hagemeyer, J. (1997). Antisocial acts in reality programming in television. Journal of Broadcasting and Electronic Media, 41, 69-75.

Potter, W. J. (1988). Three strategies for elaborating the cultivation hypothesis. Journalism Quarterly, 65, 930-939.

Potter, W. J. (1990). Adolescents' perceptions of the primary values of television programming. Journalism Quarterly, 67, 843-851.

Potter, W. J. and Chang, I. C. (1990). Television exposure measures and the cultivation hypothesis. Journal of Broadcasting and Electronic Media, 34(3), 313-333

Potter, W. J. (1990). Adolescents' perceptions of the primary values of television programming. Journalism Quarterly, 67(4), 843-851.

Potter, W. J. (1993). Cultivation theory and research: A conceptual critique. Human Communication Research, 19, 564-601.

Pratkanis, A. R., Greenwald, A. G., Leippe, M. R., and Baumgardner, M. H. (1988). In search of reliable persuasion effects: III. The sleeper effect is dead. Long live the sleeper effect. Journal of Personality and Social Psychology, 54, 203-218.

Reith, M. (1999). Viewing of crime drama and authoritarian aggression: An investigation of the relationship between crime viewing, fear, and aggression. Journal of Broadcasting and Electronic Media, 43(2), 211-221.

Rosenstein, A. W. and Grant, A. E. (1997). Reconceptualising the role of habit: A new model of television audience activity. Journal of Broadcasting and Electronic Media, 41, 324-344.

Roessler, P. and Brosius, H.-B. (2001). Do talk shows cultivate adolescents' views of the world? A prolonged-exposure experiment. Journal of Communication, 51, $143-163$.

Rouner, D. (1984). Active television viewing and the cultivation hypothesis. Journalism Quarterly, 61(1), 168-174.

Scherer, H. and Schluetz, D. (2002). Gratifikation à la minute: Die zeitnahe Erfassung von Gratifikationen. In P. Roessler, S. Kubisch, and V. Gehrau (Eds.), Empirische Perspektiven der Rezeptionsforschung (pp. 133-151). München: R. Fischer.

Schuetz, A. (1967). The phenomenology of the social world. Chicago, Ill.: Northwestern University Press.

Shanahan, J. and Morgan, M. (1999). Television and its viewers. Cultivation theory and research. Cambridge: Cambridge University Press. 
Shapiro, M. and Lang, A. (1991). Making television reality: Unconscious processes in the construction of social reality. Communication Research, 18(5), 685-705.

Shapiro, M. (1991). Memory and decision processes in the construction of social reality. Communication Research, $\overline{18(1), 3}-24$.

Sheley, J. F. and Ashkins, C. D. (1981). Crime, crime news, and crime views. Public Opinion Quarterly, 45(4), 492-506.

Shrum, L. J. (1997). The role of source confusion in cultivation effects may depend on processing strategy: A comment on Mares. Human Communication Research, $\overline{24}, 349-358$.

Shrum, L. J. (2001). Processing strategy moderates the cultivation effect. Human Communication Research, 27(1), 94-120

Shrum, L. J. (1995). Assessing the social influence of television: A social cognition perspective on cultivation effects. Communication Research, 22(4), 402-429.

Shrum, L. J. (1996). Psychological processes underlying cultivation effects: Further tests of construct accessibility. Human Communication Research, 22(4), 482-509.

Shrum, L. J. and O'Guinn, T. C. (1993). Processes and effects in the construction of social reality: Construct accessibility as an explanatory variable. Communication Research, 20(3), 436-471.

Shrum, L. J., Wyer, R. S. Jr, and O'Guinn, T. C. (1998). The effects of television consumption on social perceptions: The use of priming procedures to investigate psychological processes. Journal of Consumer Research, 24, 447-459.

Tamborini, R., Zillman, D., and Bryant, J. (1984). Fear and victimization: Exposure to television and perceptions of crime and fear. In R. N. Bostrum (Ed.), Communication Yearbook 8 (pp. 492-513). Beverly Hills, CA: Sage.

Tapper, J. (1995). The ecology of cultivation: A conceptual model for cultivation research. Communication Theory, 5(1),36-57.

Thomas, W. I. and Thomas, D. S. (1928). The child in America. Behavior problems and programs. New York: Knopf.

Valkenburg, P. M. and Patiwael, M. (1998). Does watching court TV 'cultivate' people's perceptions of crime? Gazette, 60, 227-238.

Van den Bulck, J. (2003). The datasetting effect of learning fact from viewing fiction: Toward an on-line processing model of television effects. Paper presented at the Annual Conference of the International Communication Association, San Diego, USA.

Vlasic, A. (in press). Die Integrationsfunktion der Massenmedien. Begriffsgeschichte, Modelle, Operationalisierung. Wiesbaden: Westdeutscher Verlag.

Wakshlag, J., Bart, L., Dudley, J., Gorth, G., McCutcheon, J., and Rolla, C. (1983). Viewer apprehension about victimization and crime drama programs. Communication Research, 10, 195-217.

Weaver, J. and Wakshlag, J. (1986). Perceived vulnerability to crime, criminal victimization experience, and television viewing. Journal of Broadcasting and Electronic Media, 30(2), 141-158.

Woo, H.-J. and Dominick, J. R. (2001). Daytime television talk shows and the cultivation effect among U.S. and international students. Journal of Broadcasting and Electronic Media, 45(4), 598-614.

Youn, S.-M. (1994). Program type preference and program choice in a multichannel situation. Journal of Broadcasting and Electronic Media, 38, 465-475.

Zillmann, D. (1980). Anatomy of suspense. In P. H. Tannenbaum (Ed.), The entertainment functions of television (pp. 133-163). Hillsdale, NJ: Lawrence Erlbaum Associates.

Zillmann, D. and Wakshlag, J. (1985). Fear of victimization and the appeal of crime drama. In D. Zillmann and J. Bryant (Eds.), Selective exposure to communication (pp. 141-156). Hillsdale, NJ: Erlbaum. 